\title{
Melatonin and ubiquitin: what's the connection?
}

\author{
Jerry Vriend · Russel J. Reiter
}

Received: 24 March 2014 / Revised: 9 May 2014 / Accepted: 27 May 2014 / Published online: 12 June 2014

(C) Springer Basel 2014

\begin{abstract}
Melatonin has been widely studied for its role in photoperiodism in seasonal breeders; it is also a potent antioxidant. Ubiquitin, a protein also widespread in living cells, contributes to many cellular events, although the most well known is that of tagging proteins for destruction by the proteasome. Herein, we suggest a model in which melatonin interacts with the ubiquitin-proteasome system to regulate a variety of seemingly unrelated processes. Ubiquitin, for example, is a major regulator of central activity of thyroid hormone type 2 deiodinase; the subsequent regulation of $\mathrm{T} 3$ may be central to the melatonininduced changes in seasonal reproduction and seasonal changes in metabolism. Both melatonin and ubiquitin also have important roles in protecting cells from oxidative stress. We discuss the interaction of melatonin and the ubiquitin-proteasome system in oxidative stress through regulation of the ubiquitin-activating enzyme, E1. Previous reports have shown that glutathiolation of this enzyme protects proteins from unnecessary degradation. In addition, evidence is discussed concerning the interaction of ubiquitin and melatonin in activation of the transcription factor $\mathrm{NF}-\kappa \mathrm{B}$ as well as modulating cellular levels of numerous signal transducing factors including the tumor suppressor, p53. Some of the actions of melatonin on the regulatory particle of the proteasome appear to be related to its
\end{abstract}

J. Vriend $(\bowtie)$

Department of Human Anatomy and Cell Science, University of Manitoba, 745 Bannatyne Avenue, Winnipeg, MB R3E 0J9, Canada

e-mail:Vriend@ms.umanitoba.ca

\section{R. J. Reiter}

Department of Cellular and Structural Biology, University of Texas Health Science Center at San Antonio, San Antonio, TX, USA inhibition of the calcium-dependent calmodulin kinase II, an enzyme which reportedly copurifies with proteasomes. Many of the actions of melatonin on signal transduction are similar to those of a proteasome inhibitor. While these actions of melatonin could be explained by a direct inhibitory action on the catalytic core particle of the proteasome, this has not been experimentally verified. If our hypothesis of melatonin as a general inhibitor of the ubiquitin-proteasome system is confirmed, it is predicted that more examples of this interaction will be demonstrated in a variety of tissues in which ubiquitin and melatonin co-exist. Furthermore, the hypothesis of melatonin as an inhibitor of the ubiquitin-proteasome system will be a very useful model for clinical testing of melatonin.

Keywords Ubiquitination - Transcription factor . Signal transduction · VEGF - AKT · Protein degradation . Mitochondria $\cdot$ Calmodulin

\section{Introduction}

From an evolutionary point of view both melatonin and ubiquitin are very ancient. From a functional point of view both contribute to a variety of cellular processes requiring modulation of specific proteins.

Melatonin is an indole synthesized in the pineal gland from serotonin. It was isolated and identified by Lerner and coworkers in 1958 [1]. Since its discovery, melatonin's role in modulating reproductive status of seasonal breeders has been extensively studied $[2,3]$. Its secretion is related to changes in natural (or laboratory) photoperiod. It has also been studied extensively as an antioxidant. Melatonin acts, at least in part, through inhibition of adenylate cyclase and $\mathrm{Ca}^{+2}$ [4-7]. Because of its receptor-independent scavenging 
Fig. 1 The enzymes of ubiquitination. E1 is the ubiquitinactivating enzyme. $\mathrm{E} 2$ is a ubiquitin-conjugating enzyme, while $\mathrm{E} 3$ is a ubiquitin ligase

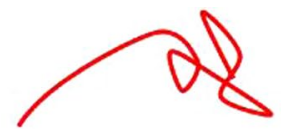

Deubiquitination

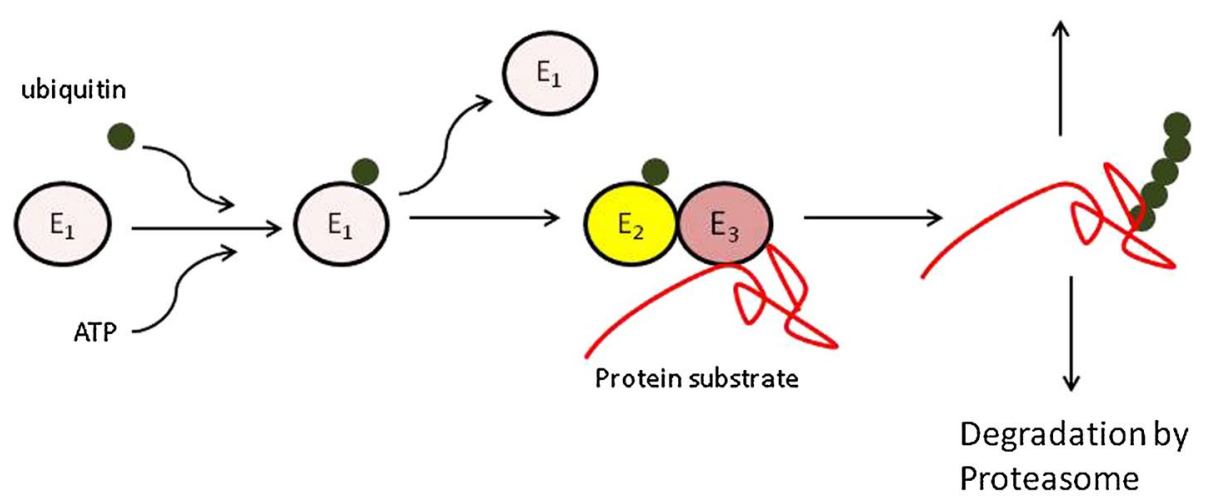

Fig. 2 The components of the proteasome. The regulatory particle (lid, hinge and base) contains subunits which bind ubiquitin, subunits which deubiquitinate and unfold proteins prior to degradation, and subunits which translocate proteins to the core particle, and subunits which open the gate the in alpha ring of the core particle. The rpt ring is a ring of six ATPase enzymes. The core particle consists of two outer rings, the alpha rings, and two inner rings, the beta rings, each with seven subunits. The proteolytic enzymes are found in the $\beta_{1}, \beta_{2}$ and $\beta_{5}$ subunits of the beta rings

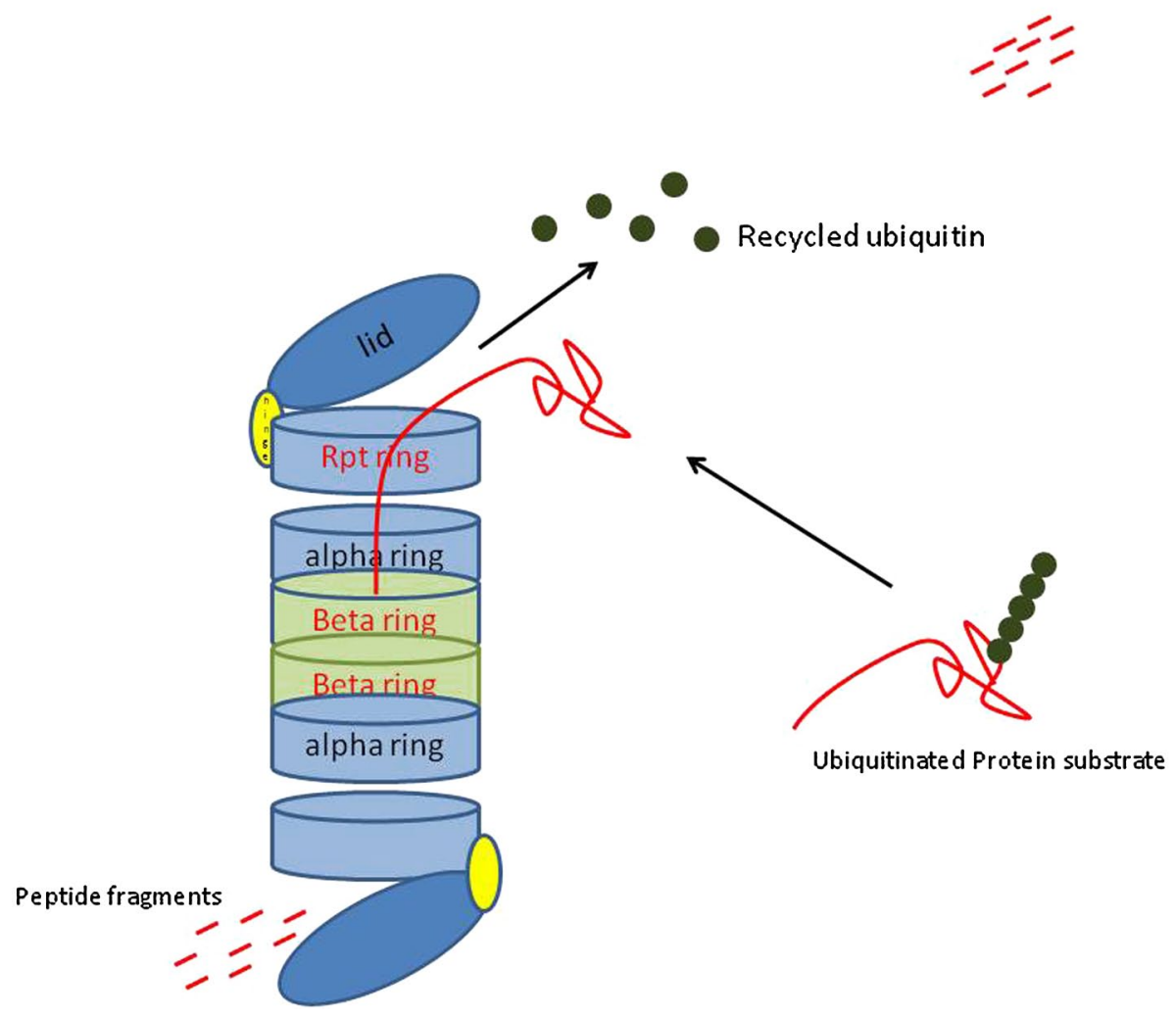

actions and the widespread occurrence of melatonin receptors [7], melatonin influences many physiological systems.

Melatonin has also been detected in all plants that have been examined $[8,9]$. Treating the roots of the apple tree (Malus hupehensis) with melatonin was recently reported to alter protein degradation and to increase photosynthetic activity [10]. Evidence has been presented that melatonin is synthesized in bacteria, as well as in mitochondria and chloroplasts both of which are believed to have been derived from bacteria when the latter were engulfed by prokaryotes $[11,12]$. In these subcellular organs, melatonin is considered to function to protect cells and organelles from oxidative stress.

Ubiquitin is a protein identified in 1975 as an adenylate cyclase-stimulating polypeptide and reported as probably universally found in living cells [13]. Because of its widespread distribution, ubiquitin contributes to a variety of cellular functions including: the immune response, cell cycle regulation, DNA transcription, control of DNA damage response proteins, modulation of cell surface receptors, 
protein repair and recycling of damaged proteins. In mitochondria, the ubiquitin-proteasome system is responsible for degrading a co-activator protein, PGC-1a, which together with transcription factors controls mitochondrial and nuclear gene transcription [14]. Thus, the ubiquitinproteasome system modulates the machinery of energy metabolism. Recent studies suggest that in plants the ubiquitin-proteasome system may contribute to the regulation of chloroplast biogenesis [15, 16].

The addition of ubiquitin (ubiquitination or ubiquitylation) to a protein (Fig. 1) can contribute to degradation via the proteasome or can alter its functional activity $[17,18]$. In its capacity in the repair and the clearance of damaged proteins, the ubiquitin-proteasome system is a very significant part of the antioxidant defence processes [19]. The ubiquitin-proteasome system is illustrated schematically in Figs. 1 and 2. The ubiquitination of a protein requires ATP, an activating enzyme, E1, a conjugating enzyme, E2, and an ubiquitin ligase, E3 (Fig. 1). The proteasome is a cylindrical cellular complex that recognizes proteins tagged by ubiquitin and contains enzymes which break down these proteins, while recycling ubiquitin. Figure 2 schematically illustrates the components of the proteasome as it relates to ubiquitin-mediated protein degradation. The molecular structure of the proteasome has been described in detail in recent reviews [20, 21].

It has been pointed out that proteasome regulation (inhibition, activation, modulation) has the potential for contributing to the control of a number of diseases including cancer [22].

In the present paper, we review few reports that show an interaction of melatonin with the ubiquitin-proteasome system and present a hypothesis concerning the general cellular mechanism of action of melatonin. Currently, there is very little information that provides direct evidence for an effect of melatonin on the ubiquitin-proteasome system or on the enzymes involved in ubiquitination of proteins.

\section{Melatonin/ubiquitin interaction in Plasmodium falciparum}

Hotta and colleagues [23] demonstrated a melatonininduced increase of the parasite $P$. falciparum in mice. Furthermore, they found that the circadian rhythm of melatonin concentrations in the host provided a signal-inducing synchronization of the Plasmodium life cycle. Plasmodium replication is synchronized with the host circadian rhythm to avoid the immune response of the host. Since melatonin was found to modulate the Plasmodium cell cycle, these investigators suggested that melatonin antagonists should be investigated as potential anti-malarial drugs. More recently, melatonin was reported to be implicated in activation of gene transcription for the ubiquitin-proteasome system in the parasite P. falciparum [24]. In these studies, melatonin was found to increase the transcription of the ubiquitin-activating enzyme, E1, as well transcription of the ubiquitin ligase, E3, and expression of the transcription factor PFNF-YB. Melatonin signaling in this system was reported as probably involving cAMP, $\mathrm{Ca}^{2+}$, and protein kinases [23, 25]. An alternative explanation for the role of melatonin in this model, i.e., that melatonin increases transcription factors via a direct inhibitory effect on the proteasome, could be inferred from the illustration in the report of Lima and colleagues [24].

\section{Melatonin/ubiquitin interaction in photoperiodic regulation of thyroid hormone deiodinase}

Ubiquitin is a major regulator of thyroid hormone type 2 deiodinase (type 2 iodothyronine deiodinase) and hence a major regulator of central conversion of thyroxine (T4) to T3; activation and inactivation of type 2 deiodinase are regulated by ubiquitination and deubiquitination [26, 27]. The ubiquitinated form of type 2 deiodinase is inactivated in proteasomes [28] or activated by deubiquitination. Deubiquitination in the proteasome is associated with enzymes in the proteasome lid and at the entrance to the Rpt ring (see Fig. 2) [21]. Tissue type 2 deiodinase is substantially increased in hypothyroidism [28-30]. Control of the deiodinase by the ubiquitination/deubiquitination switch contributes to a mechanism which maintains appropriate tissue-specific levels of T3 [31] in a variety of organs and tissues, including the brain.

In seasonal breeders (including birds, rodents and sheep), T3 regulation is reported to be central to seasonal changes in reproduction, body weight and metabolism [32]. In rodents and sheep, melatonin has been reported by a number of investigators to regulate type 2 or type 3 deiodinases [32-39]. None of these investigators apparently have determined the role of ubiquitin or ubiquitination in melatonin-induced changes in type 2 and type 3 deiodinase. Although a role for ubiquitin in melatonin regulation of central type 2 deiodinase has not been demonstrated, such an interaction can be predicted since ubiquitination is a major factor regulating deiodinase activation and negative feedback [27]; in the hypothalamus, type 2 deiodinase is inactivated by ubiquitination. Figure 1 illustrates the role of ubiquitination and deubiquitination in regulation of a protein such as type 2 deiodinase.

In the Syrian hamster, the photoperiodic variation in type 2 deiodinase expression was shown to be melatonin dependent [34]. In this species, a single melatonin injection, timed to the late part of the daily light period, reduced type 2 deiodinase mRNA in the ependymal cells lining 
the ventrobasal part of the third ventricle [36]. Yasuo and colleagues [36] concluded that the photoperiodic gonadal response to melatonin is mediated by changes in type 2 deiodinase expression in the hypothalamus. Reduced type 2 deiodinase expression would result in reduced local (hypothalamic) production of $\mathrm{T} 3$. Other hypothalamic factors considered to be of importance in the gonadal response of hamsters to melatonin injections include kisspeptin [40] and catecholamines [41-43]. The maintenance of neuronal levels of the rate-limiting enzymes for catecholamine synthesis, tyrosine hydroxylase, and serotonin synthesis, tryptophan hydroxylase, is also regulated by the ubiquitinproteasome system [44-47]. The expression of kisspeptin and the number of kisspeptin cells in the arcuate nucleus of the hypothalamus was recently reported to be sensitive to T3 levels in Siberian hamsters [48]. Thus, while there is no evidence of direct regulation of kisspeptin by ubiquitin, it appears to be indirectly regulated by the effect of ubiquitin on type 2 deiodinase activity.

A review of the similarities between the actions of melatonin on gonadal systems and thyroid hormones in Syrian hamsters was presented in 1983 by Vriend [49] and led to the hypothesis of a common site of action in the brain for the effects of melatonin on the thyroid and gonadal systems of Syrian hamsters. Based on the reports showing that melatonin inhibits type 2 deiodinase in the hypothalamus of Syrian hamsters $[34,36]$ and that ubiquitin is a major regulator of type 2 deiodinase, these studies should be reevaluated. Saita et al. [50] suggested that adequate thyroid hormone levels were required for normal GnRH release. $\mathrm{GnRH}$ content of the mediobasal hypothalamus is reportedly increased following short photoperiod exposure of female hamsters [51]. These studies are consistent with central (hypothalamic) modification of type 2 deiodinase by melatonin through the ubiquitin-proteasome system.

Effects of melatonin on serum and pituitary prolactin and growth hormone should also be re-evaluated in terms of the effects of melatonin and ubiquitin on central deiodinase activity. Serum and pituitary prolactin levels in male hamsters are reduced by both melatonin and hypothyroidism [52]. An interaction of melatonin and thyroid hormone levels on reproductive status of female hamsters was also reported [53]. Growth hormone levels in hamsters are regulated by both thyroid hormone levels and by melatonin [54].

In male hamsters, the TRH content of the hypothalamus was found to be significantly increased by short photoperiod or by daily timed melatonin injections [52]. The presence of an intact pineal gland may be a factor in regulating photoperiodic changes in hypothalamic TRH in the hamster [55]. In this species, melatonin appears to be interfering with the feedback system of thyroid hormones on TRH by its effects on central deiodinase activity. Ubiquitin appears to regulate type 2 deiodinase in all tissues that it is found.

\section{Melatonin/ubiquitin interaction in oxidative stress}

Melatonin is mentioned as a neuroprotective agent in Parkinson's disease in a report that mentions dysregulation of the ubiquitin system and the accumulation of an abnormal form of alpha synuclein in neurons [56]. Also, the pathological Lewy bodies observed in Parkinson's disease contain both synuclein and ubiquitin [57].

Modulation of the ubiquitin-proteasome system appears to be a major way for reducing the formation of oxygenbased radical species [58]. In at least one form of Parkinson's disease, there is a mutated E3 ubiquitin ligase, resulting in decreased ability to remove proteins toxic to dopaminergic neurons $[59,60]$. The ubiquitin-proteasome system also plays a role in Alzheimer's disease; the abnormal protein amyloid fibers in Alzheimer's have been suggested to be a product of a defect in the ubiquitin-proteasome system [58]. The antioxidant melatonin has been administered to Alzheimer's patients in an attempt to protect them from amyloid toxicity [61]. These investigators did not consider the possibility that the melatonin-induced improvements in these patients could be due to melatoninmediated modulation of the ubiquitin-proteasome system.

Jahngen-Hodge and colleagues [62] suggested that the cellular redox status modulates protein ubiquitination, by reversible S-thiolation. During oxidative stress, the ratio of oxidized glutathione to reduced glutathione ratio increases, concurrent with a decrease in the ubiquitin-activating enzyme, E-1 and ubiquitin conjugates. Later, evidence was presented by others of the involvement of S-glutathiolation in transcription [63] and the view that S-glutathiolation was part of a general mechanism of redox signal transduction controlling gene expression [64]. According to a model provided by Biswas and colleagues [65], glutathiolation of the E1 and/or E2 components of an ubiquitinated protein protects it from unnecessary degradation.

Melatonin has been reported to increase tissue levels of glutathione peroxidase [66, 67], an enzyme that metabolizes glutathione (an antioxidant) to its oxidized form [68] and to increase the mRNA for glutathione peroxidase [69, $70]$ in the rat brain. The possible interaction of ubiquitin in this effect of melatonin has not been directly tested. Extrapolating from the model of Biswas and colleagues [65], we predict that melatonin modifies a component of the ubiquitin-proteasome system. The functional significance of this would be to demodulate activation of proteins and to protect necessary enzymes from degradation by the ubiquitinproteasome system. 
Zhang and Sidhu [71] have studied a number of inhibitors of the ubiquitin-proteasome system. According to these investigators ubiquitin activation could be inhibited or blocked at three points: (a) binding of ATP to the E1 enzyme, (b) formation of the E1-ubiquitin complex (by targeting the thiol group, (c) Interfering with the interaction between E1 and E2 enzymes (see Fig. 1). It is suggested that melatonin interacts with the thiol group of the E1-ubiquitin complex.

\section{Melatonin/ubiquitin interaction in mitochondria}

As mentioned above, in mitochondria the ubiquitin-proteasome system is responsible for degrading a co-activator protein PGC-1a, which together with transcription factors controls mitochondrial and nuclear gene transcription [14]. Austin and St-Pierre [72] also describe PGC-1a as an inducer of mitochondrial biogenesis. They point out that PGC-1a also stimulated the expression of ROS-detoxifying enzymes and hence is a major regulator of free radical removal. In neuronal cell cultures, melatonin has been shown to stimulate the deacetylation of PGC-1a [73]. Hardeland and colleagues [74] interpret this as evidence that mitochondrial biogenesis is stimulated by melatonin. Deacetylation of PGC-1a apparently depends on the SIRT1 protein, a protein that is upregulated by melatonin [75]; it is also upregulated by estradiol, apparently via the ubiquitin-proteasome system [76]. It is predicted that melatonin and the ubiquitin-proteasome system interact in regulating mitochondrial biogenesis and in inducing the expression of ROS-detoxifying enzymes.

\section{Melatonin/ubiquitin interaction in brown fat}

In seasonal hibernating animals melatonin is reported to be a signal related to increases in brown fat [77] and thermogenesis. This was recently shown to be the case when giving daily melatonin injections to rats led to the conversion of white fat to brown fat [78]. Tan et al. [77] noted that conversion of $\mathrm{T} 4$ to $\mathrm{T} 3$ by type 2 deiodinase in brown fat contributes to the mechanism of heat production. Tan et al. [77] as well as Hardeland et al. [74] have pointed out that thermogenesis in brown adipose tissue depends on the expression of the mitochondrial uncoupling protein UCP1 and have indicated the potential importance (but lack of data) relating melatonin to UCP1. A role for ubiquitination in turnover of UCP1 has been reported [79]. Furthermore, the transcriptional protein PGC-1a has been shown to increase UCP1 expression [80]. Thus, it appears that an interaction of melatonin and the ubiquitin-proteasome system is important in modulating brown fat cell metabolism and thermogenesis related to brown fat heat production.

\section{Melatonin/ubiquitin and NF- $\mathrm{KB}$}

Nuclear factor kappa B is a transcription factor that is found in most animal cell types. It is involved in the cellular reactions to oxidative stress, immune responses and cytokine production and apoptosis. It is activated by the ubiquitin-proteasome system by a process in which the inhibitor of NF-KB is degraded [81-86].

Many of the effects of melatonin on the immune system and on inflammation also are mediated by NF- $\mathrm{kB}[74$, 87, 88]. Melatonin reduces NF- $\mathrm{KB}$ binding in spleen [89]. A number of laboratories report melatonin-induced inhibi-

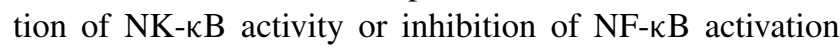
[90-100]. These results suggest an interaction of melatonin and the ubiquitin- proteasome system in the activation of $\mathrm{NF}-\kappa \mathrm{B}$. Another interpretation is that melatonin is a natural inhibitor of NF-KB.

\section{Similarities between melatonin action and a proteasome inhibitor}

Melatonin shares several features with proteasome inhibitors such as bortezomib. We have already documented the inhibitory action of melatonin on NF- $\kappa \mathrm{B}$ and the role of the proteasome in activating NF- $\kappa \mathrm{B}$. Melatonin can also induce accumulation of the tumor suppressor factor p53 [101], of the stress-related enzyme JNK [102], and of the pro-apoptotic proteins Bax and caspase-3 [103] in cancer cells. It decreases the activity of the protein kinase, AKT [104], decreases the activity of the angiogenic factor, VEGF [105], and activates the transcription factor Nrf-2 [106]. These actions are all expected of an inhibitor of the proteasome [107]. Figure 3 illustrates the various actions accounted for by melatonin as an inhibitor of the ubiquitinproteasome system.

\section{Calmodulin kinase, melatonin, and the proteasome}

In addition to binding to membrane receptors, MT1 and MT2, melatonin also binds to calmodulin [108, 109]. Benitez-King and colleagues [110] reported data showing melatonin as an inhibitor of calcium-dependent calmodulin kinase II (CaMKII) protein phosphorylation. Inhibition of CAMKII activity was also reported in the suprachiasmatic nuclei of rats [111]. More recently, the inhibitory action of melatonin on CAMKII was documented in human hepatocellular carcinoma cells [112]. 
Fig. 3 Melatonin as an inhibitor of the ubiquitin proteasome system. Proteasome inhibition could account for many of the diverse and seemingly unrelated actions of melatonin

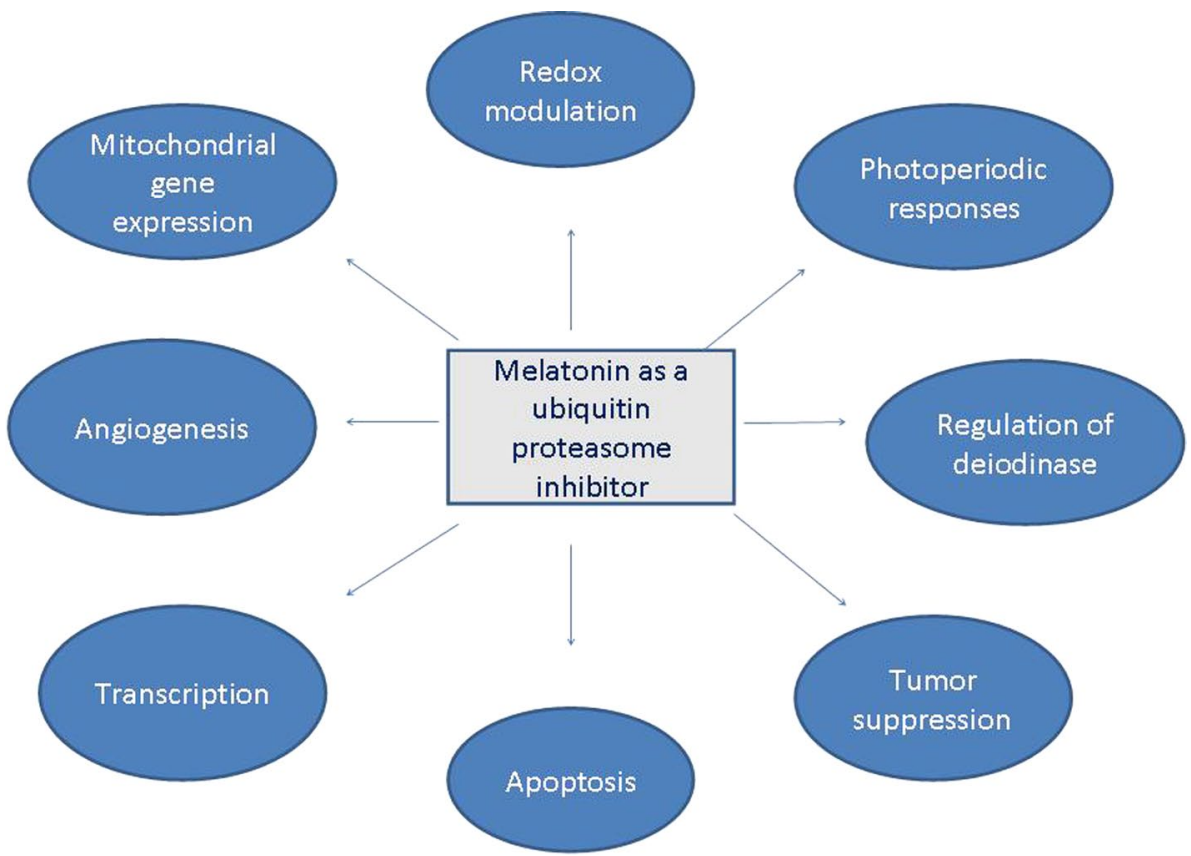

Bingol and colleagues [113] reported that CaMKII copurifies with proteasomes of the brain, and was precipitated with proteasomal subunit Rpt6 antibodies. According to these investigators, CaMKII acts as a scaffold to recruit proteasomes to spines of neurons. Rpt6 (see the Rpt ring in Fig. 2) is one of the ATPases involved in the protein unfolding, translocation, and possibly opening of the gate in the core catalytic particle of the proteasome, prior to degradation [114]. The Rpt ATPases, together with ATP, provide energy for these processes. Sha and colleagues [115] reported that protein kinase A (PKA) and CaMKII phosphorylate Rpt6, in cells resulting in enhanced degradation of proteins by the proteasome. They suggested that phosphorylation has a major role in regulation of the proteasome. More recently Jarome and colleagues [116] found that CaMKII (but not PKA) increased phosphorylation of the Rpt6 subunit protein and increased proteasome activity in rat brain tissue.

These data suggest that the melatonin/calmodulin interaction and non-receptor-mediated actions of melatonin may be more important in modulating proteasome activity than classical signal transduction pathways mediated through MT1 and MT2 melatonin receptors. However, classical melatonin-stimulated pathways that influence the activity of protein kinases have yet to be examined for their role in regulating the complex process of ubiquitination.

\section{Ubiquitin hypothesis of melatonin action}

We present the hypothesis of a general cellular action of melatonin through the ubiquitin-proteasome system. In our model, melatonin modulates ubiquitin activation required for cellular processing of proteins and inhibits proteasomal activity. We predict that testing this hypothesis will result in significant findings on melatonin signaling, whether or not the hypothesis is confirmed.

We propose that melatonin, by maintaining glutathione levels, protects ubiquitinated proteins from degradation by stimulation of S-glutathiolation of the ubiquitin-activating enzyme, E1.

In our model, melatonin inhibition of the ubiquitin-proteasome system has a major role in protecting cells from oxidative stress.

We predict that the ubiquitination/deubiquitination switch is important for the regulation of hypothalamicreleasing factors during melatonin-mediated changes in seasonal photoperiodic breeders. This switch is important for regulating thyroid hormone feedback through modulation of type 2 deiodinase and hence influencing central T3. Furthermore, in this model, melatonin control of type 2 deiodinase and T3 modulates TRH and LHRH release from the hypothalamus. Modulation of these releasing factors in turn could account for the melatonin-induced alterations in pituitary hormones including TSH, GH, PRL, and gonadotropins. In other species, the interaction of melatonin and ubiquitin is predicted to be of more significance under hypothyroid and hyperthyroid conditions, situations under which deiodinase activity is downregulated or upregulated.

Tissue levels of phosphorylated tyrosine hydroxylase and phosphorylated tryptophan hydroxylase are processed by the ubiquitin-proteasome system. A melatonin/ubiquitin interaction would, at least partially, account for the body 
of literature showing effects of melatonin on hypothalamic content of dopamine and norepinephrine, and on serotonin turnover.

Ubiquitination also appears to be involved in mediation of the antioxidant effects of melatonin. If melatonin has a general effect on proteasomes, it would be expected to modulate cellular levels of a number of signal transducing proteins including p53, VEGF, Bcl-2, BAX and AKT1, all of which are influenced by both melatonin and the ubiquitin-proteasome system. Consistent with these reports is the conclusion that melatonin acts like a proteasome inhibitor (Fig. 3). Further studies are necessary to determine whether inhibition of the proteasome is caused by the interaction of melatonin and CAMKII with the RPT ring of the proteasome or whether melatonin, like a proteasome inhibitor, acts directly on the beta ring of the catalytic core. Indeed, if this hypothesis is confirmed the effects of melatonin on many systems will be demonstrated to be mediated through the ubiquitin-proteasome system and melatonin may be clinically useful in diseases which respond to proteasome inhibitors.

\section{References}

1. Lerner AB, Case JD, Takahashi Y, Lee TJ, Mori W (1958) Isolation of melatonin, the pineal gland factor that lightens melanocytes. J Am Chem Soc 80:2587

2. Reiter RJ, Fraschini F (1969) Endocrine aspects of the mammalian pineal gland: a review. Neuroendocrinology 5:219-255

3. Shi L, Li N, Bo L, Zu Z (2013) Melatonin and hypothalamicpituitary-gonadal axis. Curr Med Chem 20:2017-2031

4. von Gall C, Stehle JH, Weaver DR (2002) Mammalian melatonin receptors: molecular biology and signal transduction. Cell Tissue Res 309:151-162

5. de Faria Poloni J, Feltes BC, Bonatto D (2011) Melatonin as a central molecule connecting neural development and calcium signaling. Funct Integr Genomics 11:383-388

6. Chan KH, Wong YH (2013) A molecular and chemical perspective in defining melatonin receptor subtype selectivity. Int J Mol Sci 14:18385-18406

7. Slominski RM, Reiter RJ, Schlabritz-Loutsevitch N, Ostrom RS, Slominski AT (2012) Melatonin membrane receptors in peripheral tissues: distribution and functions. Mol Cell Endocrinol 351:152-166

8. Dubbels R, Reiter RJ, Klenke E, Goebel A, Schnakenberg E, Ehlers $C$ et al (1995) Melatonin in edible plants identified by radioimmunoassay and by high performance liquid chromatography-mass spectrometry. J Pineal Res 18:28-31

9. Gomez FJ, Hernandez IG, Martinez LD, Silva MF, Cerutti S (2013) Analytical tools for elucidating the biological role of melatonin in plants by LC-MS/MS. Electrophoresis 34:1749-1756

10. Wang P, Sun X, Chang C, Feng F, Liang D, Cheng L, Ma F (2013) Delay in leaf senescence of Malus hupehensis by long-term melatonin application is associated with its regulation of metabolic status and protein degradation. J Pineal Res 55:424-434

11. Tan D, Manchester LC, Liu X, Rosales-Corral SA, Acuna-Castroviejo D, Reiter RJ (2013) Mitochondria and chloroplasts as the original sites of melatonin synthesis: a hypothesis related to melatonin's primary function and evolution in eukaryotes. $\mathbf{J}$ Pineal Res 54:127-138

12. Venegas C, Garcia JA, Escames G, Ortiz F, Lopez A, Doerrier C et al (2012) Extrapineal melatonin: analysis of its subcellular distribution and daily fluctuations. J Pineal Res 52:217-227

13. Schlesinger DH, Goldstein G, Niall HD (1975) The complete amino acid sequence of ubiquitin, an adenylate cyclase stimulating polypeptide probably universal in living cells. Biochemistry $14: 2214-2218$

14. Farhoud MH, Nijtmans LG, Wanders RJA, Wessels HJCT, Lasonder E, Janssen AJM et al (2012) Impaired ubiquitin-proteasome-mediated PGC-1a protein turnover and induced mitochondrial biogenesis secondary to complex-I deficiency. Proteomics 12:1349-1362

15. Huang W, Ling Q, Jarvis P (2013) The ubiquitin-proteasome system regulates chloroplast biogenesis. Commun Integr Biol 6:e23001

16. Ling Q, Huang W, Baldwin A, Jarvis P (2012) Chloroplast biogenesis is regulated by direct action of the ubiquitin-proteasome system. Science 338:655-659

17. Glickman MH, Ciechanover A (2002) The ubiquitin-proteasome proteolytic pathway: destruction for the sake of construction. Physiol Rev 82:373-428

18. Neefjes J, Groothuis TA, Dantuma NP (2004) The 2004 Nobel Prize in Chemistry for the discovery of ubiquitin-mediated protein degradation. Ned Tijdschr Geneeskd 148:2579-2582

19. Riederer BM, Leuba G, Elhajj Z (2013) Oxidation and ubiquitination in neurodegeneration. Exp Biol Med (Maywood) 238:519-524

20. Xie Y (2010) Structure, assembly and homeostatic regulation of the 26S proteasome. J Mol Cell Biol 2:308-317

21. Tomko RJ, Hochstrasser M (2013) Molecular architecture and assembly of the eukaryotic proteasome. Annu Rev Biochem 82:415-445

22. Jankowska E, Stoj J, Karpowicz P, Osmulski PA, Caczynska M (2013) The proteasome in health and disease. Curr Pharm Des 19:1010-1028

23. Hotta CT, Gararini ML, Beraldo FH, Varotti FP, Lopez C, Markus RP et al (2000) Calcium-dependent modulation by melatonin of the circadian rhythm in malarial parasites. Nat Cell Biol 2000:466-468

24. Lima WR, Holder AA, Garcia CRS (2013) Melatonin signaling and its modulation of PfNF-YB transcription factor expression in Plasmodium falciparum. Int J Mol Sci 14:13704-13718

25. Beraldo FH, Almedia FM, da Silva AM, Garcia CR (2005) Cyclic AMP and calcium interplay as second messengers in melatonin-dependent regulation of Plasmodium falciparum cell cycle. J Cell Biol 170:551-557

26. Gereben B, Goncalves C, Harney JW, Larsen PR, Bianco AC (2000) Selective proteolysis of human type 2 deiodinase: a novel ubiquitin-proteasomal mediated mechanism for regulation of hormone activation. Mol Endocrinol 14:1697-1708

27. Arrojo E, Drigo R, Fonseca TL, Werneck-de-Castro JP, Bianco AC (2013) Role of the type 2 iodothyronine deiodinase (D2) in the control of thyroid hormone signaling. Biochim Biophys Acta 1830:3956-3964

28. Steinsapir J, Harney J, Larsen PR (1998) Type 2 iodothyronine deiodinase in rat pituitary tumor cells is inactivated in proteasomes. J Clin Invest 102:895-899

29. Leonard JL, Silva JE, Kaplan MM, Mellan SA, Visser TJ, Larsen PR (1984) Acute posttranscriptional regulation of cerebrocortical and pituitary iodothyronine $5^{\prime}$-deiodinases by thyroid hormone. Endocrinology 114:998-1004

30. Costa-e-Sousa RH, Hollenberg AN (2012) Minireview: the neural regulation of the hypothalamic-pituitary-thyroid axis. Endocrinology 153:4128-4135 
31. Dentice M, Marsili A, Zavacki A, Larsen PR, Salvatore D (2012) The deiodinases and the control of intracellular thyroid hormone signaling during cellular differentiation. Biochim Biophys Acta 1830:3937-3945

32. Yasuo S, Yoshimura T, Ebihara S, Korf HW (2009) Melatonin transmits photoperiodic signals through the MT1 receptor. J Neurosci 29:2885-2889

33. Barrett P, Ebling FJ, Schuhler S, Wilson D, Ross AW, Warner A et al (2007) Hypothalamic thyroid hormone catabolism acts as a gatekeeper for the seasonal control of body weight and reproduction. Endocrinology 148:3608-3617

34. Revel FG, Saboureau M, Pevet P, Mikkelsen JD, Simonneaux V (2006) Melatonin regulates type 2 deiodinase gene expression in the Syrian hamster. Endocrinology 147:4680-4687

35. Hanon EA, Lincoln GA, Fustin JM, Dardente H, Masson-Pevet M, Morgan PJ et al (2008) Ancestral TSH mechanism signals summer in a photoperiodic mammal. Curr Biol 18:1147-1152

36. Yasuo S, Yoshimura T, Ebihar S, Korf HW (2007) Temporal dynamics of type 2 deiodinase expression after melatonin injections in Syrian hamsters. Endocrinology 148:4385-4392

37. Prendergast BJ, Pyter LM, Kampf-Lassin A, Patel PN, Stevenson TJ (2013) Rapid induction of hypothalamic iodothyronine deiodinase expression by photoperiod and melatonin in juvenile Siberian hamsters (Phodopus sungorus). Endocrinology 154:831-841

38. Herwig A, de Vries EM, Bolborea M, Wilson D, Mercer JG, Ebling FJ et al (2013) Hypothalamic ventricular ependymal thyroid hormone deiodinases are an important element of circannual timing in the Siberian hamster (Phodopus sungorus). PLoS One 8:e62003

39. Saenz de Miera C, Hanon EA, Dardente H, Birnie M, Simonneaux V, Lincoln GA et al (2013) Circannual variation in thyroid hormone deiodinases in a short-day breeder. J Neuroendocrinol 25:412-421

40. Simonneaux V, Ancel C, Poirel VJ, Gauer F (2013) Kisspeptins and RFRP-3 act in concert to synchronize rodent reproduction with seasons. Front Neurosci 7: 22 (prepublished on line)

41. Steger RW, Bartke A, Goldman BD (1982) Alterations in neuroendocrine function during photoperiod induced testicular atrophy and recrudescence in the golden hamster. Biol Reprod $26: 437-444$

42. Alexiuk NA, Vriend J (1993) Melatonin reduces dopamine content in the neurointermediate lobe of male Syrian hamsters. Brain Res Bull 32:433-436

43. Alexiuk NA, Uddin M, Vriend J (1996) Melatonin increases the in situ activity of tyrosine hydroxylase in the mediobasal hypothalamus. Life Sci 60:1300-1307

44. Kojima M, Oguro K, Sawabe K, Iida Y, Ikeda R, Yamashita A et al (2000) Rapid turnover of tryptophan hydroxylase is driven by proteasomes in RBL2H3 cells, a serotonin producing mast cell line. J Biochem 127:121-127

45. Doskeland AP, Flatmark T (2002) Ubiquitination of soluble and membrane-bound tyrosine hydroxylase and degradation of the soluble form. Eur J Biochem 269:1561-1569

46. Iida Y, Sawabe K, Kojima M, Oguro K, Nakanishi N, Hasegawa $\mathrm{H}$ (2002) Proteasome-driven turnover of tryptophan hydroxylase is triggered by phosphorylation in RBL2H3 cells, a serotonin producing mast cell line. Eur J Biochem 25:4780-4788

47. Nakashima A, Kaneko YS, Kodani Y, Mori K, Nagasaki H, Nagatsu T et al (2013) Chapter one: intracellular stability of tyrosine hydroxylase: phosphorylation and proteasomal digestion of the enzyme. Adv Pharmacol 68:3-11

48. Henson JR, Carter SN, Freeman DA (2013) Exogenous T3 elicits long day-like alterations in testis size and the RFamides kisspeptin and gonadotropin-inhibitory hormone in short-day Siberian hamsters. J Biol Rhythm 28:193-200
49. Vriend J (1983) Evidence for pineal gland modulation of the neuroendocrine-thyroid axis. Neuroendocrinology 36:68-78

50. Saita E, Tohei A, Jin WZ, Takahashi S, Suzuki AK, Watanabe $\mathrm{G}$ et al (2005) Effects of hypothyroidism on gonadal function after transition of short day photoperiod in male golden hamsters (Mesocricetus auratus). J Reprod Dev 49:87-97

51. Kumar MS, Chen CL, Besch EL, Simpkins JW, Estes KS (1982) Altered hypothalamic dopamine depletion rate and LHRH content in noncyclic hamsters. Brain Res Bull 8:33-36

52. Vriend J, Wasserman RA (1986) Effects of afternoon injections of melatonin in hypothyroid male Syrian hamsters. Neuroendocrinology 42:498-503

53. Vriend J, Bertalanffy FD, Ralcewicz TA (1987) The effects of melatonin and hypothyroidism on estradiol and gonadotropin levels in female Syrian hamsters. Biol Reprod 36:719-728 Erratum, Biol Reprod 37: 257

54. Vriend J, Borer KT, Thliveris JA (1987) Melatonin: its antagonism of thyroxine's antisomatotrophic activity in male Syrian hamsters. Growth 51:35-43

55. Vriend J, Wilber JF (1983) Influence of the pineal gland on hypothalamic content of TRH in the Syrian hamster. Horm Res 17:108-113

56. Singhal NK, Srivastava G, Agrawal S, Jain SK, Singh MP (2012) Melatonin as a neuroprotective agent in the rodent models of Parkinson's disease: is it all set to irrefutable clinical translation? Mol Neurobiol 45:186-199

57. Perfeito R, Cunha-Oliveira T, Rego AC (2013) Revisiting oxidative stress and mitochondrial dysfunction in the pathogenesis of Parkinson's disease-resemblance to the effect of amphetamine drugs of abuse. Free Radic Biol Med 62:186-201

58. Riederer BM, Leuba G, Vernay A, Riederer IM (2011) The role of the ubiquitin proteasome system in Alzheimer's disease. Exp Biol Med (Maywood) 236:268-276

59. Kitada T, Asakawa S, Hattori N, Matsumine H, Yamamura $\mathrm{Y}$, Minoshima S et al (1998) Mutations in the parkin gene cause autosomal recessive juvenile Parkinsonism. Nature 392:605-608

60. Dias V, Junn E, Mouradian MM (2013) The role of oxidative stress in Parkinson's disease. J Parkinsons Dis Nov 19 [Epub ahead of print]

61. Lin L, Huang QX, Yang SS, Chu J, Wang JZ, Tian Q (2013) Melatonin in Alzheimer's disease. Int J Mol Sci 14:14575-14593

62. Jahngen-Hodge J, Obin MS, Gong X, Shang F, Nowell TR Jr, Gong J et al (1997) Regulation of ubiquitin-conjugating enzymes by glutathione following oxidative stress. J Biol Chem 272:28218-282226

63. Bandyopadhyay S, Starke DW, Mieyal JJ, Gronostajski RM (1998) Thioltransferase (glutaredoxin) reactivates the DNAbinding activity of oxidation-inactivated nuclear factor 1 . J Biol Chem 273:392-397

64. Rokutan K, Teshima S, Miyoshi M, Kawai T, Nikawa T, Kishi K (1998) Glutathione depletion inhibits oxidant-induced activation of nuclear factor kappa B, AP-1, and c-Jun/AFT-2 in cultured guinea-pig gastric epithelial cells. J Gastroenterol 33:645-655

65. Biswas S, Chida AS, Rahman I (2006) Redox modifications of protein-thiols: Emerging roles in cell signaling. Biochem Pharmacol 71:551-564

66. Barlow-Walden LR, Reiter RJ, Abe M, Pablos M, MenendezPelaez A, Chen LD, Poeggeler B (1995) Melatonin stimulates brain glutathione peroxidase activity. Neurochem Int 26:497-502

67. Pablos MI, Reiter RJ, Ortiz GG, Guerrero JM, Agapito MT, Chuang JI et al (1998) Rhythms of glutathione peroxidase and glutathione reductase in brain of chick and their inhibition by light. Neurochem Int 32:9-75 
68. Reiter RJ, Melchiorri D, Sewerynek E, Poeggeler B, BarlowWalden L, Chuang J et al (1995) A review of the evidence supporting melatonin's role as an antioxidant. J Pineal Res $18: 1-11$

69. Kotler M, Rodriguez C, Sainz RM, Antolin I, Menendez-Pelaez A (1998) Melatonin increases gene expression for antioxidant enzymes in rat brain cortex. J Pineal Res 24:83-89

70. Mayo JC, Sainz RM, Antolin I, Herrera F, Martin V, Rodriguez C (2002) Melatonin regulation of antioxidant gene expression. Cell Mol Life Sci 59:1706-1713

71. Zhang W, Sidhu SS (2014) Development of inhibitors in the ubiquitination cascade. FEBS Lett 588:356-367

72. Austin S, St-Pierre J (2012) PGC1a and mitochondrial metabolism: emerging concepts and relevance in ageing and neurodegenerative disorders. J Cell Sci 125:4963-4971

73. Tajes M, Gutierrez-Cuesta J, Ortuno-Sahagun D, Camins A, Pallas M (2009) Antiaging properties of melatonin in an in vitro murine senescence model: involvement of the sirtuin 1 pathway. J Pineal Res 47:228-237

74. Hardeland R, Cardinali DP, Srinivasan V, Spence DW, Brown GM, Pandi-Perumal SR (2011) Melatonin: a pleiotropic, orchestrating regulator molecule. Prog Neurobiol 93:350-384

75. Gutierrez-Cuesta J, Tajes M, Jimenez A, Coto-Montes A, Camins A, Pallas M (2008) Evaluation of potential pro-survival pathways regulated by melatonin in a murine senescence model. J Pineal Res 45:497-505

76. Han L, Wang P, Zhao G, Wang M, Chen J, Tong T (2013) Upregulation of SIRT1 by $17 \beta$-estradiol depends on ubiquitinproteasome degradation of PPAR- $\gamma$ mediated by NEDD4-1. Protein Cell 4:310-321

77. Tan D, Manchester LC, Fuentes-Broto L, Paredes SD, Reiter RJ (2011) Significance and application of melatonin in the regulation of brown adipose tissue metabolism: relation to human obesity. Obes Rev 12:167-188

78. Jimenez-Aranda A, Fernandez-Vazquez G, Campos D, Tassi M, Velasco-Perez L, Tan DX et al (2013) Melatonin induces browning of inguinal adipose tissue in Zucker diabetic fatty rats. J Pineal Res 55:416-423

79. Clarke KJ, Adams AE, Manzke LH, Pearson TW, Borchers CH, Porter RK (2012) A role for ubiquitinylation and the cytosolic proteasome in turnover of mitochondrial uncoupling protein 1 (UCP1). Biochim Biophys Acta 1817:1759-1767

80. Wei P, Pan D, Mao C, Wang YX (2012) RNF34 is a cold-regulated E3 ubiquitin ligase for PGC-1a and modulates brown fat cell metabolism. Mol Cell Biol 32:266-275

81. Traenckner EB, Wilk S, Baeuerle PA (1994) A proteasome inhibitor prevents activation of NF-kappa B and stabilizes a newly phosphorylated form of I kappa B-alpha that is still bound to NF-kappa B. EMBO J 13:5433-5441

82. Chen ZJ (2005) Ubiquitin signalling in the NF-kappaB pathway. Nat Cell Biol 7:758-765

83. Gilmore TD (2006) Introduction to NF-kappa B: players, pathways, perspectives. Oncogene 25:6680-6684

84. Brasier AR (2006) The NF- $\kappa$ B regulatory network. Cardiovasc Toxicol 6:111-130

85. Perkins ND (2007) Integrating cell-signalling pathways with NF- $\kappa \mathrm{B}$ and IKK function. Nat Rev Mol Cell Biol 8:49-62

86. Skaug B, Jiang X, Chen ZJ (2009) The role of ubiquitin in NF$\mathrm{kB}$ regulatory pathways. Ann Rev Biochem 78:769-796

87. Reiter RJ, Calvo JR, Karbownik M, Qi W, Tan DX (2000) Melatonin and its relation to the immune system and inflammation. Ann N Y Acad Sci 917:376-386

88. Calvo JR, Gonzalez-Yanes C, Malonado MD (2013) The role of melatonin in the cells of the innate immunity: a review. J Pineal Res 55:103-120
89. Chuang JI, Mohan N, Meltz ML, Reiter RJ (1996) Effect of melatonin on NF-kappa-B DNA binding activity in the rat spleen. Cell Biol Int 20:687-692

90. Mohan N, Sagedhi K, Reiter RJ, Meltz ML (1995) The neurohormone melatonin inhibits cytokine, mitogen and ionizing radiation induced NF-kappa B. Biochem Mol Biol Int 37:1063-1070

91. Gilad E, Wong HR, Zingarelli B, Virag L, O'Connor M, Salzman AL et al (1998) Melatonin inhibits expression of the inducible isoform of nitric oxide synthase in murine macrophages: role of inhibition of NF-kappaB activation. FASEB J 12:685-693

92. Bruck R, Aeed H, Avni Y, Shirin H, Matas Z, Shahmurov M et al (2004) Melatonin inhibits nuclear factor kappa B activation and oxidative stress and protects against thioacetamide induced liver damage in rats. J Hepatol 40:86-93

93. Li JH, Yu JP, Yu HG, Xu XM, Yu LL, Liu J et al (2005) Melatonin reduces inflammatory injury through inhibiting NFkappaB activation in rats with colitis. Mediators Inflamm 31:185-193

94. Huang SH, Cao XJ, Wei W (2008) Melatonin decreases TLR3mediated inflammatory factor expression via inhibition of NF-kappa B activation in respiratory syncytial virus-infected RAW264.7 macrophages. J Pineal Res 45:93-100

95. Jung KH, Hong SW, Zheng HM, Lee DH, Hong SS (2009) Melatonin downregulates nuclear erythroid2-related factor 2 and nuclear factor-kappaB during prevention of oxidative liver injury in a dimethylnitrosamine model. J Pineal Res 47:173-183

96. Choi EY, Jin JY, Lee JY, Choi JI, Choi IS, Kim SJ (2011) Melatonin inhibits Prevotella intermedia lipopolysaccharide-induced production of nitric oxide and interleukin- 6 in murine macrophages by suppressing NF- $\mathrm{B}$ and STAT1 activity. J Pineal Res 50:197-206

97. Bekyarova G, Apostolova M, Kotzev I (2012) Melatonin protection against burn-induced hepatic injury by down-regulation of nuclear factor kappa B activation. Int J Immunopathol Pharmacol 25:591-596

98. Qin W, Lu W, Li H, Yuan X, Li B, Zhang Q, Xiu R (2012) Melatonin inhibits IL $1 \beta$-induced MMP9 expression and activity in human umbilical vein endothelial cells by suppressing NF-кB activation. J Endocrinol 214:145-153

99. Shi D, Xiao X, Wang J, Liu L, Chen W, Fu L et al (2012) Melatonin suppresses proinflammatory mediators in lipopolysaccharide-stimulated CRL 1999 cells via targeting MAPK, NF-кB, c/EB $\beta$, and p300 signaling. J Pineal Res 53:154-165

100. Min KJ, Jang JH, Kwon TK (2012) Inhibitory effects of melatonin on the lipopolysaccharide-induced $\mathrm{CC}$ chemokine expression in BV2 murine microglial cells are mediated by suppression of AKT-induced NF- $\mathrm{KB}$ and STAT/GAS activity. J Pineal Res 52:296-304

101. Martin-Renedo J, Mauriz JL, Jorquera F, Ruiz-Andres O, Gonzalez P, Gonzalez-Gallego J (2008) Melatonin induces cell cycle arrest and apoptosis in hepatocarcinoma HEPG2 cell line. J Pineal Res 45:532-540

102. Carbajo-Pescador S, Garcia-Palomo A, Martin-Renedo J, Piva M, Gonzalez-Gallego J, Mauriz JL (2011) Melatonin modulation of intracellular signalling pathways in hepatocarcinoma HepG2 cell line: role of the MT1 receptor. J Pineal Res 51:463-471

103. Perdomo J, Cabrera J, Estevez F, Loro J, Reiter RJ, Quintana J (2011) Melatonin induces apoptosis through a caspase-dependent but reactive oxygen species-independent mechanism in human leukemia Molt-3 cells. J Pineal Res 55:195-206

104. Wang J, Xiao X, Zhang Y, Shi D, Chen W, Fu L et al (2012) Simultaneous modulation of COX-2, p300, Akt, and Apaf-1 
signaling by melatonin to inhibit proliferation and induce apoptosis in breast cancer cells. J Pineal Res 53:77-90

105. Alvarez-Garcia V, Gonzalez A, Alonso-Gonzalez C, MartinezCampa C, Cos S (2013) Antiangiogenic effects of melatonin in endothelial cell cultures. Microvasc Res 87:25-33

106. Aparicio-Soto M, Alarcon-de-la-Lastra C, Cardeno A, SanchezFidalgo S, Sanchez-Hidalgo M (2014) Melatonin modulates microsomal PGE synthase 1 and NF-E2 related factor-2-regulated antioxidant enzyme expression in LPS-induced murine peritoneal macrophages. Br J Pharmacol 171:134-144

107. Holkova R, Grant S (2012) Proteasome inhibitors in mantle cell lymphoma. Best Pract Res Clin Haematol 25:133-144

108. Benitez-King G, Huerto-Delgadillo L, Anton-Tay (1993) Binding of 3H-melatonin to calmodulin. Life Sci 53:201-207

109. Ouyang H, Vogel H (1998) Melatonin and serotonin interactions with calmodulin: NMR, spectroscopical and biochemical studies. Biochim Biophys Acta 1383:37-47

110. Benitez-King G, Rios A, Martiniez A, Anton-Tay F (1996) In vitro inhibition of $\mathrm{Ca}^{2+} /$ calmodulin-dependent kinase II activity by melatonin Biochim. Biophys Acta 1290:191-196

111. Fukunaga K, Horikawa K, Shibata S, Takeuchi Y, Miyamoto E (2002) $\mathrm{Ca}^{2+} /$ calmodulin-dependent protein kinase II-dependent long-term potentiation in the rat suprachiasmatic nucleus and its inhibition by melatonin. J Neurosci Res 15:799-807

112. Carocci A, Catalano A, Bruno C, Lovece A, Roselli MG, Cavalluzzi MM et al (2013) N-(Phenoxyalkyl) amides as M(1) and MT(2) ligands: antioxidant properties and inhibition of $\mathrm{Ca}(2+) /$ CaM-dependent kinase II. Bioorg Med Chem 21:847-851

113. Bingol B, Wang CF, Arnott D, Cheng D, Peng J, Sheng M (2010) Autophosphorylated CAMKII alpha acts as a scaffold to recruit proteasomes to dendritic spines. Cell 140:567-578

114. Lander G, Estrin E, Matyskiela ME, Bashore C, Nogales E, Martin A (2012) Complete subunit architecture of the proteasome regulatory particle. Nature 482:186-191

115. Sha Z, Peth A, Goldberg AL (2011) Keeping proteasomes under control: a role for phosphorylation in the nucleus. Proc Natl Acad Sci USA 108:18573-18574

116. Jarome TJ, Kwapis JL, Ruenzel WL, Helmstetter FJ (2013) CaMKII, but not protein kinase A, regulates RPT6 phosphorylation and proteasome activity during the formation of long-term memories. Front Behav Neurosci 7:115 